\title{
Jogos "geoeducativos" como subsídio à Geoconservação no litoral sul de Pernambuco (NE Brasil): uma proposta
}

\author{
"Geoeducational" games as support for geoconservation at southern coast of Pernambuco (Northeast \\ BRAZIL): A PROPOSAL.
}

Thaís de Olivelra Guimarães ${ }^{1}$, Gorki Mariano², Artur Abreu e Sán ${ }^{3}$

1 Progr. Pós-Grad. Geociências, Depto. Geologia. C. Tecnol. e Geoc. UFPE. 50740-530, Recife PE - thaisguimaraes.ge0@gmail.com

2 Depto. Geologia. C. Tecnol. e Geoc. UFPE. 50740-530, Recife PE - gm@ufpe.br.

3 Depto. Geologia, Univ. Trás-0s-Montes e Alto Douro; Centro Geoc. Univ. Coimbra, Quinta de Prados, 5000-801 Vila Real, Portugal - asa@utad.pt.

ABSTRACT: The interest in publicizing the geosciences is present in subjects like geodiversity, geoconservation, geoheritage, geoparks and geotourism. To popularize the abiotic elements is to make society understand their importance and help practice geoconservation measures. This work highlights the relevance of non-formal education process, and suggests ways to facilitate its assimilation by the general public, through interdisciplinary activities and the popularization of Geosciences. In order to achieve that objective, prototypes of "geoeducational games" were made, with the intention of applying them in formal and non-formal educational spaces located in the southern coast of the State of Pernambuco. Thus, a literature review was carried out, as well as on-site experiences, such as visits to museums, geoparks, and participation in workshops. Based on the knowledge acquired in this work, the importance of using specific materials directed to geodiversity and geoheritage was clear.

\section{Manuscrito:}

Recebido: 10/03/2016

Corrigido: 07/10/2016

Aceito: 09/01/2017

Citation: Guimarães T.0., Mariano G., Sá A.A.2017. Jogos "geoeducativos" como subsídio à Geoconservação no litoral sul de Pernambuco (NE Brasil): uma proposta. Terræ Didatica, 13(1):30-42. < http://www.ige.unicamp. br/terraedidatica/ $>$.

Keywords: Non-formal education, geoconservation, popularization of Geosciences, southern coast of Pernambuco.

\section{Introdução}

O presente trabalho foi desenvolvido com base em três temáticas chaves: a geoconservação, a interdisciplinaridade e a educação. Esses temas se configuram na pesquisa como pilares principais, que sustentam as questões inerentes ao patrimônio geológico, a geoeducação e a inclusão das comunidades locais.

No que tange ao patrimônio geológico, foram selecionados os principais elementos da geodiversidade da faixa litorânea Sul do Estado de Pernambuco, definida na divisão costeira do Estado como Setor Sul ou Litoral Sul de Pernambuco, composto por sete municípios: Cabo de Santo Agostinho, Ipojuca, Sirinhaém, Rio Formoso, Tamandaré, Barreiros e São José da Coroa Grande, com uma extensão de praias de aproximadamente $110 \mathrm{~km}$.

Têm-se como objetivos promover meios não formais de inserir na sociedade regional a responsabilidade de conservar o patrimônio geológico e os principais valores a ele agregados, mostrando-lhe, por exemplo, a importância de alguns minerais e rochas. Busca-se com esta proposta conscientizar crianças, jovens e adultos de que estes elementos são importantes para desvendar a história da Terra, sendo as rochas e os solos o substrato para todos os seres vivos.

Por outro lado, sabe-se que a conscientização a favor dos elementos abióticos não se configura como uma tarefa fácil, principalmente pelo seu caráter inanimado. Vê-se que há uma comoção e sensibilização bem maior quando se trata de biosfera, principalmente de animais, com os quais a sociedade comumente manifesta empatia. Entretanto, mesmo com maior carga emocional, vê-se o quanto os biólogos e ambientalistas tem dificuldade de conscientizar a população com relação à importância e o equilíbrio da biodiversidade.

Nesse sentido, foi apresentada uma proposta de popularização das Geociências e contributo a geoconservação a partir de processos educativos não formais, utilizando para isso recursos denominados neste trabalho de "jogos geoeducativos", que irão abordar de forma interdisciplinar temas geológicos, 
geográficos, ambientais, históricos e culturais.

Nesse contexto, foram selecionados e confeccionados três jogos, escolhidos a partir do critério de popularidade e facilidade para serem trabalhados e adaptados à temática, sendo eles um jogo da memória, um dominó e um quebra-cabeças. $\mathrm{O}$ intuito é que esses jogos acrescentem um maior conhecimento dos elementos da geodiversidade da região (rochas e processos geológicos), da biodiversidade (vegetação de mangue), história e cultura local (ruínas e monumentos históricos), a partir de atividades lúdicas que poderão ser realizadas em espaços educativos formais (escolas) e não formais (museus e centros comunitários) no Litoral Sul de Pernambuco - Nordeste do Brasil.

\section{Materiais e Métodos}

Inicialmente buscou-se a conceituação das temáticas da educação não formal, interdisciplinaridade e popularização das Geociências focando principalmente no tripé: geodiversidade, patrimônio geológico e geoconservação.

O trabalho constou de quatro etapas:

I) Seleção da área a ser trabalhada, pesquisa bibliográfica detalhada do meio físico da região e demais assuntos referentes à temática dos 5G's (geodiversidade, patrimônio geológico, geoconservação, geoturismo e geoparques). Buscou-se ainda informações sobre alguns aspectos sociais referentes ao turismo, história e cultura regional, bem como outros relacionados com a interdisciplinaridade e a popularização das Geociências;

II) Atividades de imersão e vivência acerca das temáticas trabalhadas, que constaram de recolha de material e visitas a geoparques e museus onde são desenvolvidas atividades com jogos, atividades lúdicas e geoeducativas semelhantes as propostas agora apresentadas;

III) trabalho de campo na área de estudo com análise dos elementos da geodiversidade e patrimônio geológico local, visitas a museus (museus do Una e Engenho Massangana), escolas e unidades de conservação, bem como conversas informais com moradores e visitantes acerca das temáticas;

IV) Seleção e confecção dos materiais geoeducativos com base nas atividades prévias.

Após o levantamento dos potenciais recursos didáticos que poderiam ser utilizados, foram selecionados jogos tradicionais, com baixo custo financeiro, fáceis de serem encontrados e que estão presentes normalmente no dia a dia das crianças, seja em casa ou na escola. Foram eles: i) jogo da memória; ii) dominó e iii) quebra-cabeças.

Posteriormente à seleção dos jogos buscaram-se formas de adaptá-los à temática das Geociências, por meio de um trabalho que envolveu atividade de campo para registros fotográficos, trabalho de gabinete com pesquisa bibliográfica, tratamento digital e montagem das imagens para possibilitar a adaptação aos jogos.

Foram utilizados materiais em madeira reciclada e a adaptação foi feita a partir de fotografias de elementos da geodiversidade e do patrimônio geológico do Litoral Sul de Pernambuco, bem como elementos da biodiversidade, da história e da cultura local, a fim de construir uma proposta interdisciplinar levando em consideração as relações existentes entre os elementos supracitados.

Citam-se como exemplos os elementos da biodiversidade que dependem diretamente dos elementos da geodiversidade, como os arenitos de praia (beachrocks) que servem de substrato a espécies marinhas, entre elas os ouriços-do-mar (Echinometra lucunter). Vale ressaltar também as ruínas históricas construídas no Litoral Sul de Pernambuco com rochas locais, a exemplo do granito utilizado nas edificações e os arenitos de praia usados nos adornos e trabalhados em cantarias.

O granito é uma rocha mais resistente e por isso a utilização nas paredes e estruturas das edificações, enquanto o arenito de praia (beachrocks) são rochas menos resistentes e mais fáceis de serem entalhadas na arte da cantaria e utilizadas em portas, janelas e soleiras. Todos esses elementos em algum momento se inter-relacionam e podem ser trabalhados de maneira interdisciplinar.

Com o levantamento fotográfico realizado foi feito o tratamento digital e montagem das imagens para a impressão. De posse do material impresso foram realizados os recortes e a colagem manual, utilizando materiais simples como tesoura, cola, tintas e pincéis (Fig. 1).

Neste momento o foco principal das atividades se deteve na seleção e confecção dos jogos, a princípio voltadas aos indivíduos das comunidades locais, pretendendo-se alcançar desde o público infantil, adolescentes, adultos e idosos, trabalhando o material com diferentes abordagens. A partir deste material, o trabalho poderá avançar para as etapas futuras, com a aplicação dos recursos geoeducativos e posterior avaliação dos resultados. 

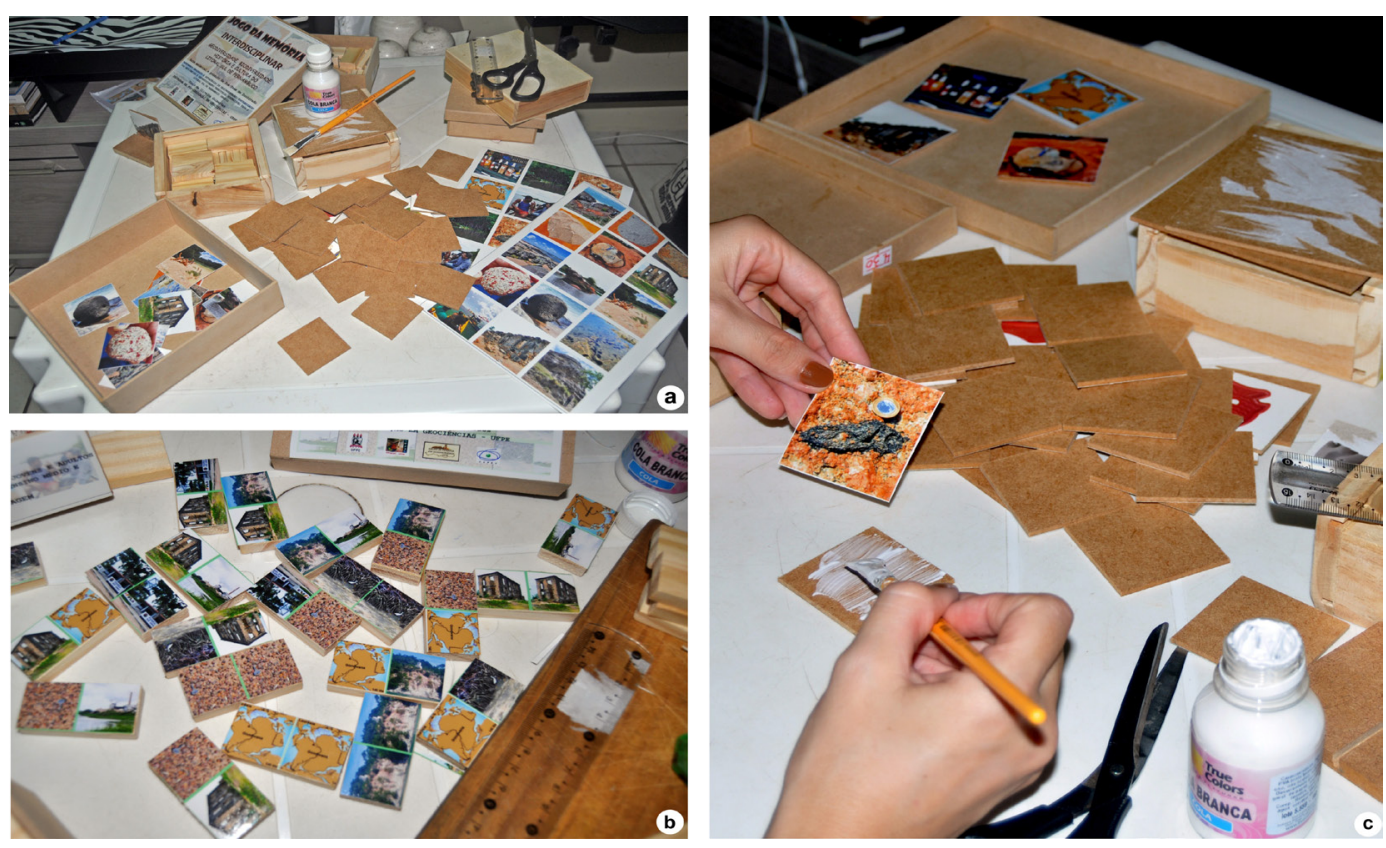

Figura 1. Elaboração do material geoeducativo. (a) Imagens a serem recortadas e coladas nas peças do jogo da memória; (b) Peças do dominó prontas; (c) Colagem de fotografia utilizando cola branca em uma das peças do jogo da memória.

\section{Enquadramento Conceitual}

O conceito de interdisciplinaridade é ainda hoje discutido e chega a ser confundido com outros conceitos etimologicamente parecidos, como transdisciplinaridade e multidisciplinaridade. Para que um tema, um objeto ou uma abordagem se configure como interdisciplinar basta que duas ou mais disciplinas, ou áreas de conhecimentos estabeleçam intencionalmente vínculos entre si, com o objetivo de alcançar um conhecimento mais vasto, diversificado e integrado (Coimbra 2000). Para este autor "o vocábulo interdisciplinaridade apresenta-se despretensioso na sua origem, ambíguo na sua acepção corrente e complexo na sua aplicação".

É talvez essa complexidade de relacionar disciplinas ou áreas de conhecimento distintas que assusta um pouco os adeptos do ensino tradicional. No entanto, ser complexo não é o mesmo que ser complicado. Pode-se dizer que a complexidade está diretamente relacionada ao mundo empírico, da incerteza, da incapacidade de conceber uma ordem absoluta (Morin 2011). Logo, induzir o pensamento complexo incentiva o questionamento e o pensamento crítico, bem como a possibilidade de formar pessoas capazes de questionar e pensar de forma multidimensional.

A partir do século XIX, assistiu-se a uma fragmentação do conhecimento entre os seres humanos e natureza, influenciados por pensadores como
Descartes, Galileu, Leibniz ou Newton (Gonçalves 2008). Essa corrente cartesiano-newtoniana foi responsável pela criação de diversas especializações e pela visão mecanicista do mundo. A natureza vista simbolicamente como uma máquina a ser desvendada e desmontada por linhas de pesquisa cada vez mais específicas (Coimbra 2000).

Essa fragmentação dos conhecimentos ainda faz parte da realidade atual. Nesse sentido, a abordagem interdisciplinar representa importante ferramenta para o aprendizado e uma melhor compreensão do mundo, uma vez que, a partir da interdisciplinaridade, é possível suprimir a visão reducionista e fragmentada das disciplinas. Nesse sentido, a utilização de recursos didáticos se configura como uma alternativa a mais favorecendo uma melhor percepção acerca dos conhecimentos adquiridos.

A associação de valores históricos e culturais às Geociências, intimamente relacionados aos elementos do meio abiótico, pode promover o despertar de uma consciência conservacionista e humanista (Guimarães \& Mariano 2014). Esse tipo de abordagem complexa extrapola a perspectiva disciplinar, exigindo um conhecimento holístico, trabalhando em conjunto a problemática ambiental relacionada aos elementos naturais e as realidades sociais. Este processo tem como um dos objetivos reunificar a Ciência admitindo uma reordenação da realidade atual (Vargas 2000). 
Com base numa concepção holística e interdisciplinar foram desenvolvidos trabalhos em geoconservação, que englobam os processos de educação formal, informal e não formal. A abordagem foi focada no elo naturalmente existente entre meio físico e meio social, mostrando o quanto estão entrelaçados e o quanto são indivisíveis (Guimarães \& Mariano 2014, Rozakis et al. 2015, Donslund \& Lemkow 2015).

Nas escolas em especial têm-se o hábito de ensinar isolando os objetos de seu meio ambiente, apartando as disciplinas ao invés de integrá-las e reconhecer suas relações. Segundo Morin (2012) somos obrigados a "reduzir o complexo ao simples, isto é, a separar o que está ligado; a decompor e não a recompor; e a eliminar tudo que causa desordens ou contradições em nosso entendimento".

Nas Geociências a necessidade de se trabalhar de forma interdisciplinar é enriquecedora, uma vez que a dinâmica terrestre requer a integração de várias áreas do conhecimento e fragmentá-la pode acarretar na simplificação do aprendizado, não no sentido de torná-lo simples, ou fácil como menciona Morin (2012), mas no sentido de negligenciar informações que seriam importantes. Desse modo, a popularização das Geociências é uma importante ferramenta interdisciplinar que, quando trabalhada no processo educativo forma ou não formal, é capaz de obter resultados muito positivos.

\section{Educação e processos educativos}

Ao unir os pilares que norteiam os projetos direcionados à geodiversidade e ao patrimônio geológico, a educação é sem dúvidas a força motriz desse sistema. A partir de investimentos na educação evoluem as atividades interdisciplinares, ações de conservação e popularização do conhecimento científico. A educação é considerada um direito humano fundamental e essencial para o exercício de todos os outros direitos. A partir dela é promovida a liberdade individual e o empoderamento dos indivíduos, bem como benefícios importantes ao seu desenvolvimento.

No entanto, mesmo com todo avanço social e tecnológico, a desigualdade entre alguns países é grande e milhões de crianças e adultos permanecem privados de oportunidades educacionais. Trata-se de um instrumento poderoso, mediante o qual adultos marginalizados (econômica e socialmente) e crianças podem livrar-se da pobreza e inserir-se na sociedade como cidadãos ativos ${ }^{1}$.

A educação de forma geral, representativa do processo de desenvolvimento intelectual dos seres humanos (em especial em crianças), é de tal forma abrangente que prescinde de adjetivos (Gaspar 2002). Para este autor a educação é um processo único, normalmente associado à escola. Contudo, para que haja um maior entendimento de seus mecanismos é importante que se façam algumas distinções.

Nesse contexto, o processo educacional é complexo e não se restringe à escola, como muitos ainda pensam. $\mathrm{O}$ aprendizado acontece a partir de casa desde o nascimento, está presente no cotidiano das pessoas e sob múltiplas formas no meio em que se vive (Gaspar 1992). Assim, fica mais que evidente que a educação extrapola os muros da escola e da educação formal. Desta forma, o processo educativo pode ocorrer de modo formal, não formal e informal. Sendo que estas formas de aprendizado têm sido discutidas por muitos pesquisadores em Educação e Popularização das Ciências (Coombs \& Ahmed 1974, Dib 1987, Gaspar 1992, Marandino et al. 2004, Dierking 2005, Nelson et al. 2006, Pinto 2007, Navas 2008).

Com relação à educação não formal os pesquisadores são praticamente unânimes em atribuir-lhe três características: i) é organizada (ao contrário da educação informal); ii) opera fora da estrutura do sistema formal e está geralmente livre de suas normas; e iii) é direcionada a interesses particulares e necessidades de aprendizagens de qualquer subgrupo de uma população. Além dessas três características as atividades não formais são bastante diversas (Coombs \& Ahmed 1974).

Para educação não formal não existe um consenso ou definição única. As interpretações, de acordo com Pinto (2007) podem variar de acordo com as diferentes culturas, tradições nacionais ou outras características inerentes a cada país. A educação não formal pode ser diferenciada da educação formal em nível de estrutura, organização, tipo de reconhecimento e qualificação que lhe conferem. Compreende-se o processo educativo não formal como um complemento, e não contraditório ou como alternativa ao sistema formal, devendo ser desenvolvida em conjunto com a educação formal e informal.

Quanto à educação informal, esta corresponde às experiências do cotidiano e é aprendida ao longo

1 http://www.unesco.org/new/en/education/themes/leading-the-international-agenda/right-to-education/ 
da vida, tenha o indivíduo estado ou não no sistema de educação formal. Ao contrário da educação formal e não formal, que possuem fins particulares, a educação informal não é sistemática e nem organizada, ocorrendo muitas vezes de forma não intencional, despretensiosa e até acidental. Trata-se de um processo importante principalmente nos primeiros anos de vida do indivíduo, quando se dá os primeiros passos e aprende-se a língua materna. O sujeito vive o processo em toda a sua existência, em casa, na escola, no trabalho, em visita a museus, bibliotecas, teatros, entre outros. Todo aprendizado é adquirido por meio da vivência e da capacidade interpretativa de cada indivíduo (Coombs \& Ahmed 1974).

Em seu documento de "Reconhecimento, Validação e Acreditação" (RVA) para a aprendizagem não formal e informal, a UNESCO demonstra a importância dos processos educacionais ao longo da vida dos indivíduos e ratifica que estes, são fundamentais para sua missão de promover o direito de cada indivíduo ao acesso da educação (UNESCO 2014).

Lamentavelmente a Geologia e suas áreas de conhecimento não ocupam uma posição satisfatória no currículo da educação formal das escolas. Para Carneiro et al. (2004) a população está sendo privada de um conhecimento elementar e essencial. Estes autores sugerem uma proposta de organização interdisciplinar entre as disciplinas relacionadas com as ciências da natureza, incluindo, por exemplo, professores da Geografia Física, Geologia, Biologia e Física. Para isso, seria necessária também a atualização dos profissionais. Nesse sentido, os professores deveriam estar aptos para trabalhar conteúdos com questões geológicas e relacioná-las com as demais áreas das Geociências.

A bibliografia acerca das temáticas educativas é vasta, existindo pontos de concordância e consenso, mas de forma geral os pesquisadores em educação acreditam que os três processos educativos se completam. Em conformidade com a opinião de Dib (1988) acredita-se que o sistema formal de ensino necessita de mais flexibilidade e interdisciplinaridade em suas estruturas, a fim de desenvolver nos alunos a curiosidade e a capacidade crítica de pensamento. Esta, sem dúvida, não se configura uma tarefa fácil, mas é muito importante que se aposte numa interligação entre as três formas de educar: formal, não formal e informal.

Em se tratando de espaços educativos, o espaço formal é garantido por lei e organizado de acordo com os padrões formalizados, enquanto o espaço não formal de educação se refere a qualquer espaço diferente da escola onde pode haver a ação educativa. Embora pareça simples a uma primeira leitura, esta definição apresenta certa complexidade, uma vez que há inúmeros lugares "não escolares" e onde ocorrem os processos educativos (Jacobucci 2008).

Contudo, a expressão "espaços não formais de educação", vem sendo bastante utilizada por professores e demais profissionais que trabalham no âmbito da divulgação das Ciências, a fim de descrever os lugares fora da escola onde se podem desenvolver estas atividades educacionais (Jacobucci 2008).

Com base na abordagem da educação não formal percebe-se que esta representa acima de tudo um processo educativo social, de construção do indivíduo e de suas responsabilidades como cidadão, sejam elas voltadas para a sociedade ou ao ambiente natural, ocorrendo fora da obrigatoriedade dos currículos formais de ensino.

Dentre as oportunidades que as atividades não formais poderão promover está a popularização das Geociências. A partir de planos e projetos de divulgação que envolvam a sociedade é possível desenvolver a sensibilidade e curiosidade quanto ao meio natural. No caso agora estudado envolvem essencialmente os elementos da geodiversidade e do patrimônio geológico do Litoral Sul de Pernambuco.

O processo educativo não formal é optativo e induzido pelo real interesse do indivíduo. Nesse sentido, é importante o desenvolvimento de estratégias e recursos pedagógicos que dinamizem a atividade e despertem o interesse, preferencialmente de forma interdisciplinar onde o indivíduo deixe de ser apenas um receptor e passe a fazer parte direta do processo, interagindo e trocando experiências.

Em se tratando de espaços educativos, a modalidade não formal está aberta a uma infinidade de opções. Neste trabalho destacam-se as atividades em museus, centros de ciências, feiras e projetos itinerantes, cursos, workshops, palestras, entre outras atividades em que é possível deslocar-se e alcançar o participante (Fig. 2a-c). Destacam-se ainda os territórios classificados com a chancela de programas UNESCO (Geoparques, Reservas da Biosfera e espaços e sítios considerados Patrimônio da Humanidade). As atividades desenvolvidas nesses territórios, em sua maioria, visam à construção do conhecimento a partir da popularização das Geociências direcionada às inciativas de "geoeducação" 

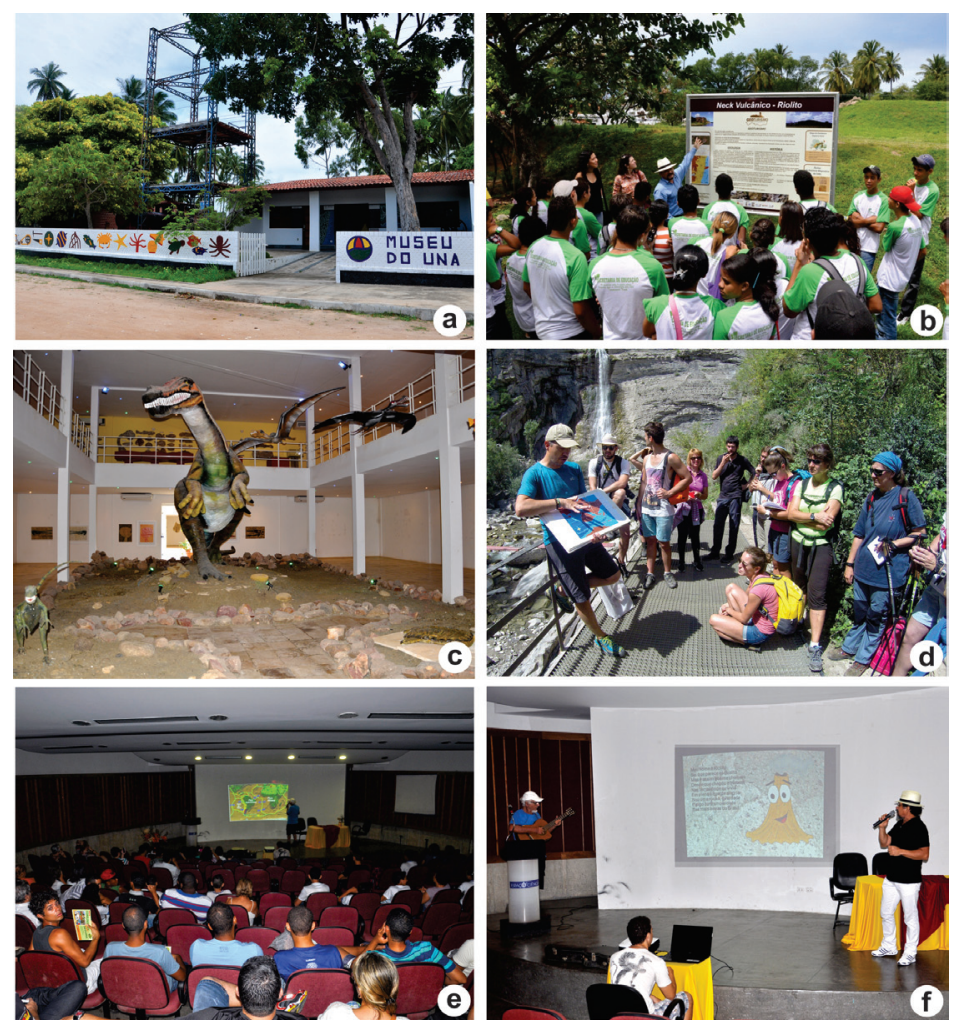

Figura 2. Espaços educativos não formais. (a) Museu do Una em São José da Coroa Grande - PE; (b) Painel informativo sobre as rochas vulcânicas do Litoral Sul de PE - fixado no Espaço Ciência em Olinda/PE; (c) Museu de Paleontologia da Universidade Regional do Cariri (URCA) - Geoparque Araripe/Ceará; (d) Curso de verão sobre Geoparques e Geoconservação no Geoparque Sobrarbe nos Pirineus - Espanha; (e-f) Palestras cantadas pelos professores do Departamento de Geologia da UFPE, Prof. Dr. Paulo Corrêa e Prof. Dr. Gorki Mariano durante o $3^{\circ}$ Mineral and Rock Fest (2014).

(Fig. 2d).

No Estado de Pernambuco, por exemplo, assiste-se não só ao surgimento como também ao crescimento de projetos relacionados à temática, de que são exemplo o Mineral and Rock Fest e o projeto "mineralogia nas escolas", ambos idealizados por um grupo de professores do Departamento de Geologia da Universidade Federal de Pernambuco (Fig. 2e-f). Contudo, esta realidade inspira cautela, sendo preciso incrementar e diversificar a formação de mais profissionais com perfil de trabalho interdisciplinar, bem como a criação, o incentivo e a liberação de recursos para que se desenvolvam mais projetos nesses moldes e se alcance um maior número de pessoas.

\section{Recursos didáticos e 0 trabalho interdisciplinar}

$\mathrm{A}$ atividade educativa não formal $\mathrm{e} \mathrm{o}$ ato de informar têm como suporte várias ferramentas, entre elas a elaboração e utilização de material impresso que tem como principal objetivo prender a atenção do público, a partir principalmente da comunicação visual e de uma linguagem textual simples, criativa, acessível, clara e objetiva, voltada essencialmente para leigos na temática abordada.

Esse material pode ser apresentado em formato de cartões postais, marca páginas, folders e cartazes informativos, guias de campo e de bolso contendo caracterização física da área e mapas com percursos pedestres, livros e cartilhas infantis contendo temas referentes à história da Terra, histórias em quadrinhos, cadernos de pinturas, puzzles para montagens (quebra-cabeças), jogos de cartas, jogos da memória ou dominó, entre outros instrumentos capazes de propiciarem um aprendizado prazeroso (Fig. 3a-d).

Nos territórios classificados como Geoparques Mundiais da UNESCO observa-se um grande volume de material impresso e em meio digital sendo produzido e disponibilizado. É comum ao chegar a um Geoparque da Rede Mundial encontrar em seus centros interpretativos e de atendimento ao turista uma vasta opção de material impresso, jogos e produtos locais, sejam para distribuição gratuita ou para venda.

Fora da rede de geoparques vê-se a elaboração desses materiais por meio de projetos de professores e pesquisadores ligados a universidades, de que é exemplo o livro ilustrado sobre as rochas vulcânicas do Litoral Sul de Pernambuco, intitulado: "Riolito, o vulcão pernambucano" (Mariano \& Barbosa 2008) (Fig. 3e) e o livro sobre o patrimônio paleontológico da região do Araripe pernambucano, intitulado "Tesouros do Araripe" (Barreto et al. 2013).

O material impresso associado a outras iniciativas de popularização e geoeducação contribuirá como um fator importantíssimo e talvez o ponto chave para a geoconservação, que é a conscientização norteada pelo conhecimento; conhecimento esse adquirido de modo não formal, de forma alegre, descontraída e sem a obrigatoriedade do ensino formal, muitas vezes em um momento de lazer, em atividades ao ar livre e de contato com a natureza, 

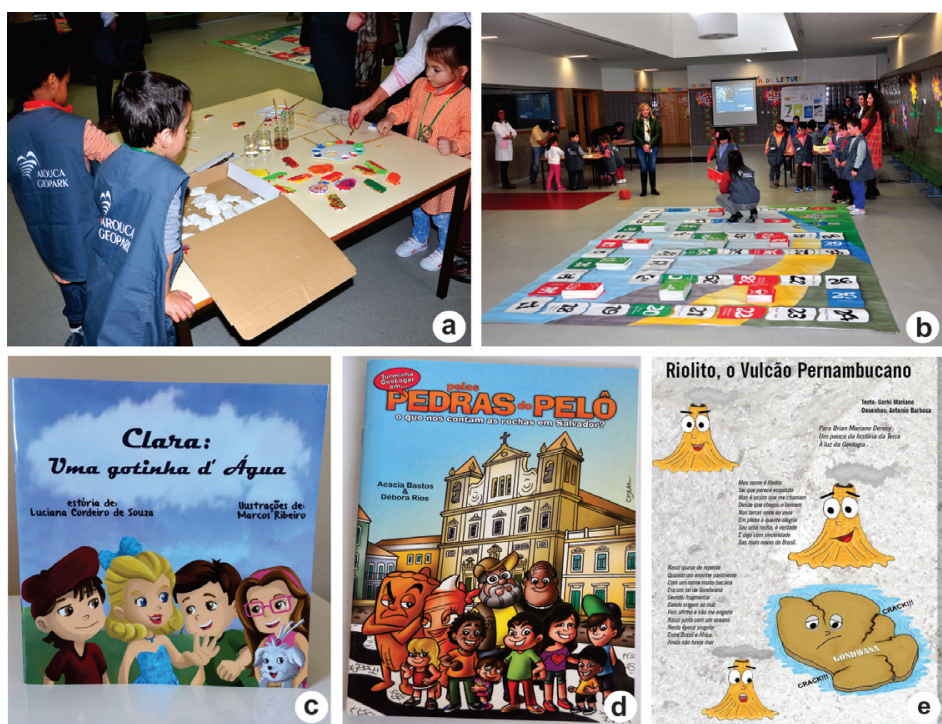

Riolito, o Vulcão Pernambucano

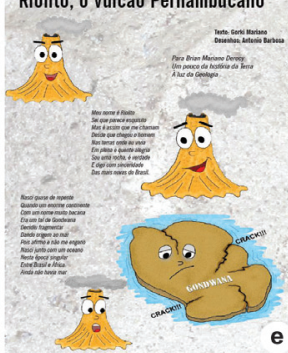

Figura 3. Alguns exemplos de atividades e recursos educativos não formais. (a-b) Atividades educativas - pinturas em réplicas de fósseis confeccionadas em gesso e jogos interativos do Geoparque Arouca/ PT; (c) História em quadrinhos aborda a questão da água e o ciclo hidrológico, texto de Luciana Cordeiro e ilustrações de Marcos Ribeiro; (d) História em quadrinhos sobre a geologia de Salvador - Bahia. Fruto da Tese de Doutorado de Acácia Bastos no âmbito do Instituto de Geociências da Universidade Federal da Bahia e Departamento de Ciências da Terra da Universidade do Minho, Braga - Portugal; (e) Livro ilustrado sobre as rochas vulcânicas do Litoral Sul de Pernambuco, intitulado "Riolito, o vulcão pernambucano" (Mariano \& Barbosa 2008).

mas também em sua própria casa, em algum museu ou até mesmo na escola.

O trabalho com recursos geoeducativos voltados para a sociedade estreita os laços entre os processos e os elementos geológicos (geodiversidade e patrimônio geológico) e rompe com o paradigma de que a geologia e suas subáreas são disciplinas meramente técnicas e voltadas para o mundo acadêmico e científico, muitas vezes de difícil compreensão.

A ciência geológica atual apresenta outras relações com a sociedade, por meio principalmente de suas subáreas do conhecimento como a geologia ambiental e as temáticas referentes aos 5G's: geodiversidade, geoconservação, geoturismo, patrimônio geológico e os geoparques (Carcavilla Urqui 2012). Essa nova abordagem do conhecimento em Geociências possui hoje, em função da criação do Programa Mundial de Geoparques UNESCO, um vínculo ainda mais forte e relevante com a sociedade.

\section{Resultados e discussão}

O Litoral Sul de Pernambuco apresenta elevado potencial para este estudo, pautado nos principais elementos da geodiversidade e seu patrimônio geológico. A faixa litorânea Sul do Estado de Pernambuco é formada pelos municípios do Cabo de Santo Agostinho, Ipojuca, Sirinhaém, Rio Formoso, Tamandaré, Barreiros e São José da Coroa Grande que somam aproximadamente $110 \mathrm{~km}$ de extensão de praias, contendo baías, falésias, estuários, restingas e ainda a ilha de Santo Aleixo, localizada a $2 \mathrm{~km}$ da costa e pertencente ao município de Sirinhaém (Fig. 4).

Esta zona costeira difere tanto do ponto de vista geológico como geomorfológico dos demais setores costeiros do Estado (Setor Norte e Metropolitano), uma vez que a geodinâmica terrestre proporcionou ao Litoral Sul maior diversidade litológica e morfologias diferenciadas, a exemplo da ilha vulcânica de Santo Aleixo e neck vulcânico de Ipojuca.

$\mathrm{Na}$ região em estudo, a geodiversidade e a história se misturam, uma vez que elementos geomorfológicos, de que é exemplo o promontório do Cabo de Santo Agostinho, uma elevação granítica de aproximadamente 60 metros, foi um ponto importantíssimo na defesa do território pernambucano durante a invasão holandesa no século XVII.

A topografia elevada e a localização estratégica (ao lado da baía e porto de Suape) favoreceu a construção de edificações militares, como fortes (Forte Castelo do Mar e Forte São Francisco Xavier), baterias (Baterias de São Jorge) e um quartel (Quartel Velho). Sobre o promontório os luso-brasileiros travaram várias batalhas e as ruínas históricas, hoje tombadas como patrimônio histórico do Estado remete a um passado de lutas e resistência.

Geologicamente a área de estudo está inserida em três domínios geológicos: i) Bacia Sedimentar de Pernambuco em sua porção centro-sul; ii) Suíte Magmática de Ipojuca; e iii) rochas neoproterozoicas do Embasamento Cristalino. Apresenta ainda sedimentos da Formação Barreiras e sedimentos do Quaternário.

A geodiversidade e o patrimônio geológico a ela associado permitem concluir que o Litoral Sul de Pernambuco apresenta relevância geológica internacional, desde logo porque se constitui um dos últimos elos entre os continentes sul-americano e 


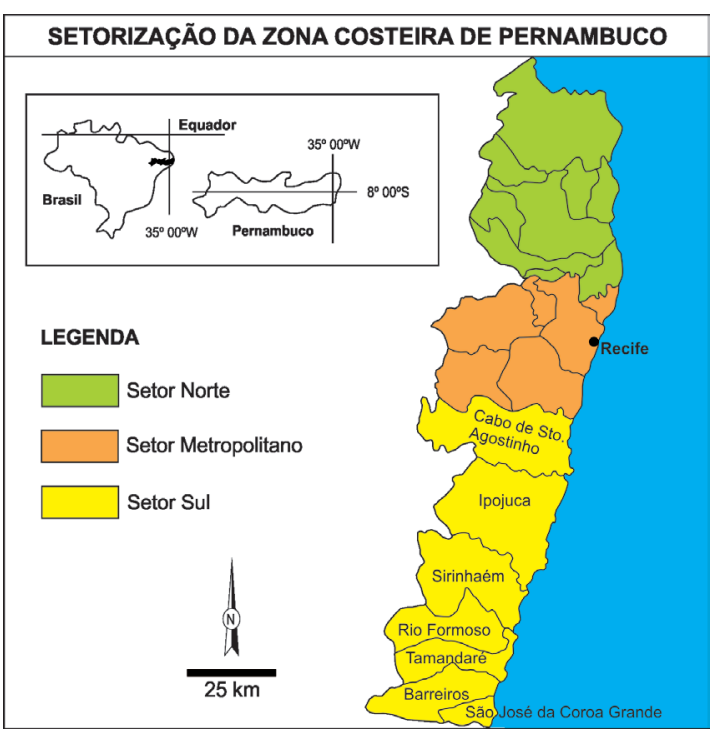

Figura 4. Mapa de localização do Litoral Sul de Pernambuco (Modificado de CPRH 2001).

africano após o fim da ruptura do mega continente Gondwana Pós-Pangeia, fato testemunhado pela ocorrência de rochas vulcânicas únicas nessa região (Lima Filho 2006). Apresenta ainda um litoral contornado por linhas de arenitos de praia (beachrocks) já citados por Darwin (1841) em sua viagem a bordo do Beagle e, posteriormente, estudados por Branner (1904), que descreveu os beachrocks de praticamente toda a costa nordestina, desde o Ceará até a Bahia.

Além disso, esta região apresenta testemunhos históricos em vários pontos do território, desde ruínas que remontam à invasão holandesa no século XVII, como fortificações e igrejas, até engenhos e usinas de cana-de-açúcar que representam a história de ascensão e queda da atividade econômica pautada na monocultura da cana-de-açúcar, que durante muito tempo constituiu-se o motor econômico de Pernambuco.

A região é ainda destino de inúmeras excursões didáticas de escolas do ensino fundamental e médio, bem como de aulas de campo realizadas por cursos de Universidades públicas e privadas da região, incluindo alunos dos cursos de Geologia, Geografia, Arqueologia, Ciências Biológicas e Turismo, entre outros.

Com base em todos esses elementos foram confeccionados e/ou adaptados a partir das especificidades da região três modelos de jogos: dominó, jogo da memória e quebra-cabeças. Cada recurso geoeducativo possui uma abordagem diferente, que dará ao educador subsídios para ministrar uma aula ou uma palestra ou qualquer outra atividade idea- lizada de forma mais lúdica e interessante (Fig. 5).

O material agora apresentado, que a princípio pode parecer destinado apenas às crianças e adolescentes, poderá ser utilizado com adultos e em particular com idosos. Atenta-se aí principalmente para a atividade do jogo da memória com os idosos. Dessa forma, mais que uma atividade saudável para a memória, configura-se como um resgate de identidade desses indivíduos, que terão a oportunidade de associar elementos que fizeram e fazem parte de suas vivências no território ao longo da sua existência.

Em outra perspectiva, por tratar-se de um material específico da região, a atividade permitirá que os envolvidos conheçam melhor o seu território, que entendam mais sobre a dinâmica terrestre que configurou as paisagens que eles veem todos os dias, bem como as rochas que fazem parte de seu cotidiano e os ecossistemas que estão presentes a caminho da escola ou de onde tiram seu sustento.

Vale ressaltar que em todos os jogos, para cada peça com uma imagem, haverá uma fotografia em tamanho 10x15 cm que ficará com o moderador ou responsável em acompanhar a atividade. Pretende-se que estas fotografias representem um acréscimo para a atividade, uma vez que recursos tecnológicos como datashow e computadores nem sempre estão disponíveis. Em casos onde as fotografias retratem minerais e rochas locais haverá ainda um kit com amostras, permitindo observação do material completo.
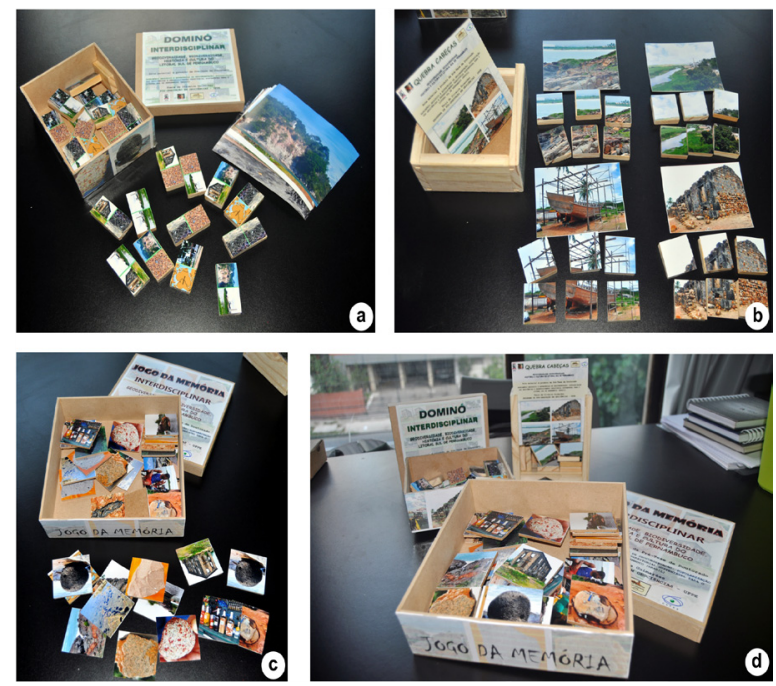

Figura 5. Jogos confeccionados para as atividades geoeducativas. (a) Dominó contendo 28 peças e sete imagens; (b) Quebra cabeças contendo 24 peças, divididas em quatro imagens para montar; (c) Jogo da memória contendo 40 peças e 20 imagens duplicadas; (d) Imagem dos jogos acondicionados em caixas. 


\section{Jogo da memória}

1. Conteúdo - 20 peças quadradas em madeira, caixa em madeira e 10 fotografias referentes as imagens das peças (cada peça foi confeccionada em pares, portanto são 20 peças e 10 imagens);

2. As fotografias retratam elementos da geodiversidade (ex: paisagens), do patrimônio geológico (ex: geossítios relevantes), elementos da biodiversidade (ex: fauna e flora local), da história (ex: ruínas históricas) e da cultura das comunidades locais (ex: cenas do cotidiano);

3. Sugere que seja jogado em até quatro participantes;

4. Público alvo: crianças partir de 3 anos, jovens, adultos e idosos.

\section{Dominó}

1. Conteúdo - 28 peças em madeira, uma caixa em madeira e 7 fotografias 10x15;

2. As fotografias retratam elementos da geodiversidade idênticas às usadas no jogo da memória acima descrito;

3. Sugere que seja jogado em até quatro participantes;

4. Público alvo: crianças a partir de 3 anos, jovens, adultos e idosos.

\section{Quebra-cabeças}

1. Conteúdo -24 peças em madeira (jogo está dividido em 04 imagens com 06 peças cada), uma caixa em madeira e 4 fotografias 10x15;

2. As fotografias retratam elementos da geodiversidade idênticas às usadas no jogo da memória acima descrito;

3. Sugere que seja jogado em até quatro participantes;

4. Público alvo: crianças partir de 3 anos, jovens, adultos e idosos.

Os jogos possuem praticamente os mesmos objetivos. Serão trabalhados todos os elementos de forma interdisciplinar, em uma abordagem apropriada à faixa etária ou perfil do grupo de indivíduos. As atividades contribuirão para um maior conhecimento da região e desenvolvimento do sentido de pertença. No caso dos indivíduos que não conhecem bem o entorno onde vivem será uma oportunidade de descoberta, enquanto que para aqueles que o conhecem será uma incrível troca de conhecimentos, que envolverá o saber popular e o conhecimento científico de forma descontraída.

Para os idosos especificamente há ainda o benefício no que se refere à saúde mental, em que a atividade poderá possibilitar o resgate de memórias e vivencias passadas. Para a abordagem com as crianças tem-se a grande responsabilidade de trabalhar de forma lúdica a importância desses elementos que representam o patrimônio geológico, histórico e cultural, de modo a incrementar as atividades formais desenvolvidas nas instituições de ensino. Quanto aos jovens e adultos, há com esses grupos uma responsabilidade a curtíssimo prazo, pois são agentes modificadores atuais.

Sugere-se também a aplicação dos jogos como uma pré-atividade, antes, por exemplo, de uma aula de campo, com indivíduos que não conhecem a região profundamente, mas que logo necessitará desse conhecimento para desempenhar outra atividade.

Vê-se que a aplicação dos jogos pode ser feita de inúmeras formas e destinadas a públicos diferentes, modificando nesse caso a abordagem. Com relação à localização, as atividades podem ser desenvolvidas em espaços educativos formais (escolas) ou não formais, a exemplo de museus, associações de moradores, lar de idosos, entre outros.

\section{Jogos na prática}

Após a confecção dos jogos buscou-se a aplicação dos mesmos. Para isso foi realizada a atividade prática dos jogos com professores de ensino básico, alunos do curso de Pós-Graduação Lato Sensu (Especialização em Ensino da Geografia) e em seguida foi realizada a excursão de campo para a região, visitando elementos que foram abordados nos jogos.

A atividade prática constou de três etapas: i) aula acerca das temáticas; ii) aplicação dos jogos e iii) preenchimento de questionários para análises posteriores (Fig. 6). Com base na análise das respostas vê-se que 18 dos entrevistados já tinha algum conhecimento acerca da temática. Para cada jogo foi feito um questionário com perguntas a respeito da qualidade, criatividade e nível de estímulo dos jogos. A maioria, um total de 17 indivíduos, acre- 

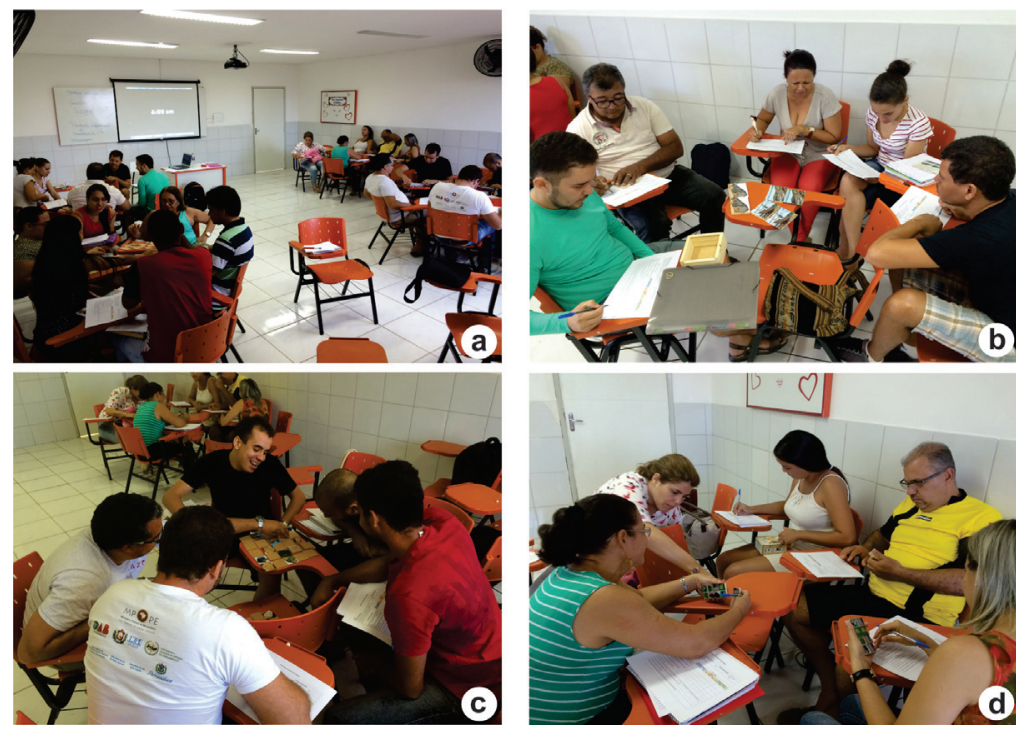

Figura 6. Aplicação dos jogos com alunos do curso de Especialização em Ensino da Geografia. Participaram da atividade 20 indivíduos, sendo 18 licenciados em geografia e dois em pedagogia.

dita que os jogos possuem função educativa e de entretenimento.

Todos os entrevistados responderam que aplicariam os jogos com seus alunos e foram feitas algumas sugestões de melhoria, como a atribuição de valores nas peças do dominó, para que em caso de empate ao final do jogo ter-se como desempatar; também foi proposto acrescentar perguntas e respostas nas peças do jogo da memória. Sugeriu-se ainda que a cada par de peças do jogo da memória encontrado pelo jogador, o mesmo descreva para os colegas a paisagem ou elemento contido na imagem (Tab. 1).

A atividade tendo os jogos como recursos geoeducativos foi considerada positiva e bem aceita pelo grupo. Uma semana após a atividade prática foi realizada uma aula de campo para o litoral do município do Cabo de Santo Agostinho, mais precisamente a vila histórica de Nazaré, inserida no Litoral Sul de Pernambuco, onde foi realizada uma trilha, tendo como responsável uma professora da Geografia. A atividade foi acompanhada ainda por um aluno do curso de Arqueologia e morador local, que contribuiu com informações sobre os aspectos históricos e arqueológicos da área. No campo os alunos
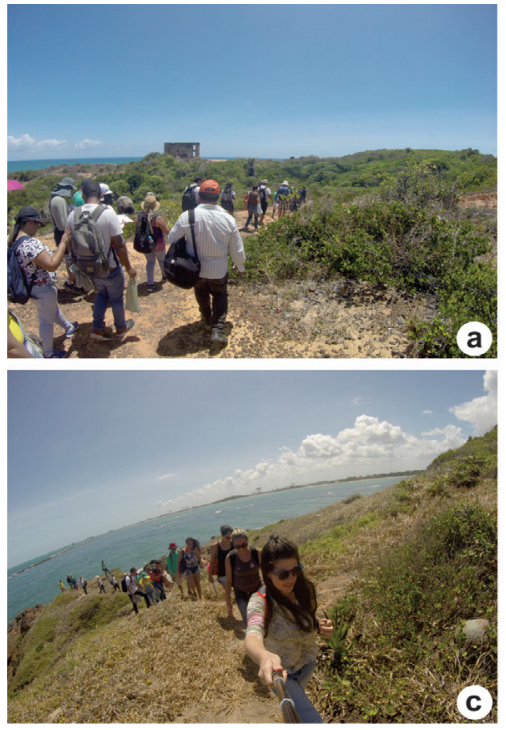

Figura 7. Aula de campo após a atividade prática de aplicação dos jogos. (a-c) Alunos durante a trilha; (d) participação do Arqueólogo, e morador da área, Lucas Rocha (canto esquerdo da imagem).
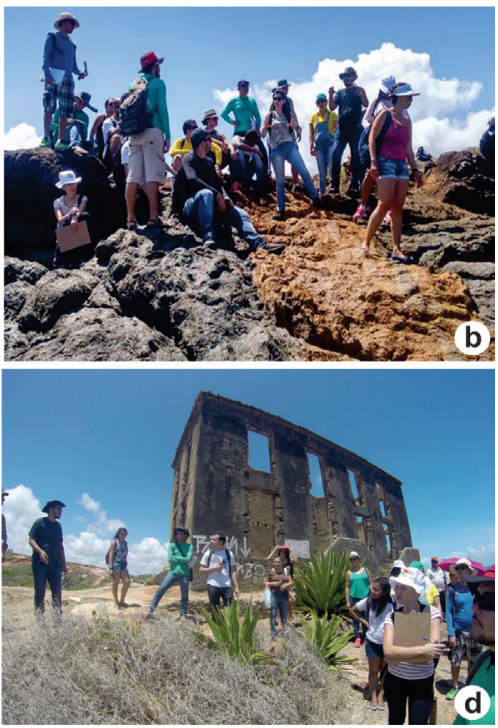

puderam reconhecer e vivenciar muitos dos elementos que foram abordados e vistos durante a atividade prática, reforçando assim o aprendizado em sala de aula (Fig. 7).

Os jogos aqui apresentados foram trabalhados com um público específico, alunos de Pós-Graduação, em sua maioria professores do ensino fundamental e médio. Nesse sentido, veem-se duas vantagens nos resultados obtidos. Em primeiro lugar, a possibilidade de aprendizado e atualização desses profissionais. A segunda vantagem é que, além de absorverem o conhecimento para si, esses professores são agentes multiplicadores e poderão trabalhar com seus alunos atividades desta natureza, disseminando a atividade lúdica e não convencional e contribuindo ativamente para uma geoconservação não pela proibição de uso, mas pelo conhecimento e aquisição do sentido de pertença.

Considera-se que os professores representam público muito importante para se trabalhar os jogos, não apenas por meio da aplicação, como em forma de workshops, oficinas e capacitação para esses profissionais, transformando-os não apenas em agentes multiplicadores, mas, tornando-os acima de tudo, incentivadores da geoconservação e da 


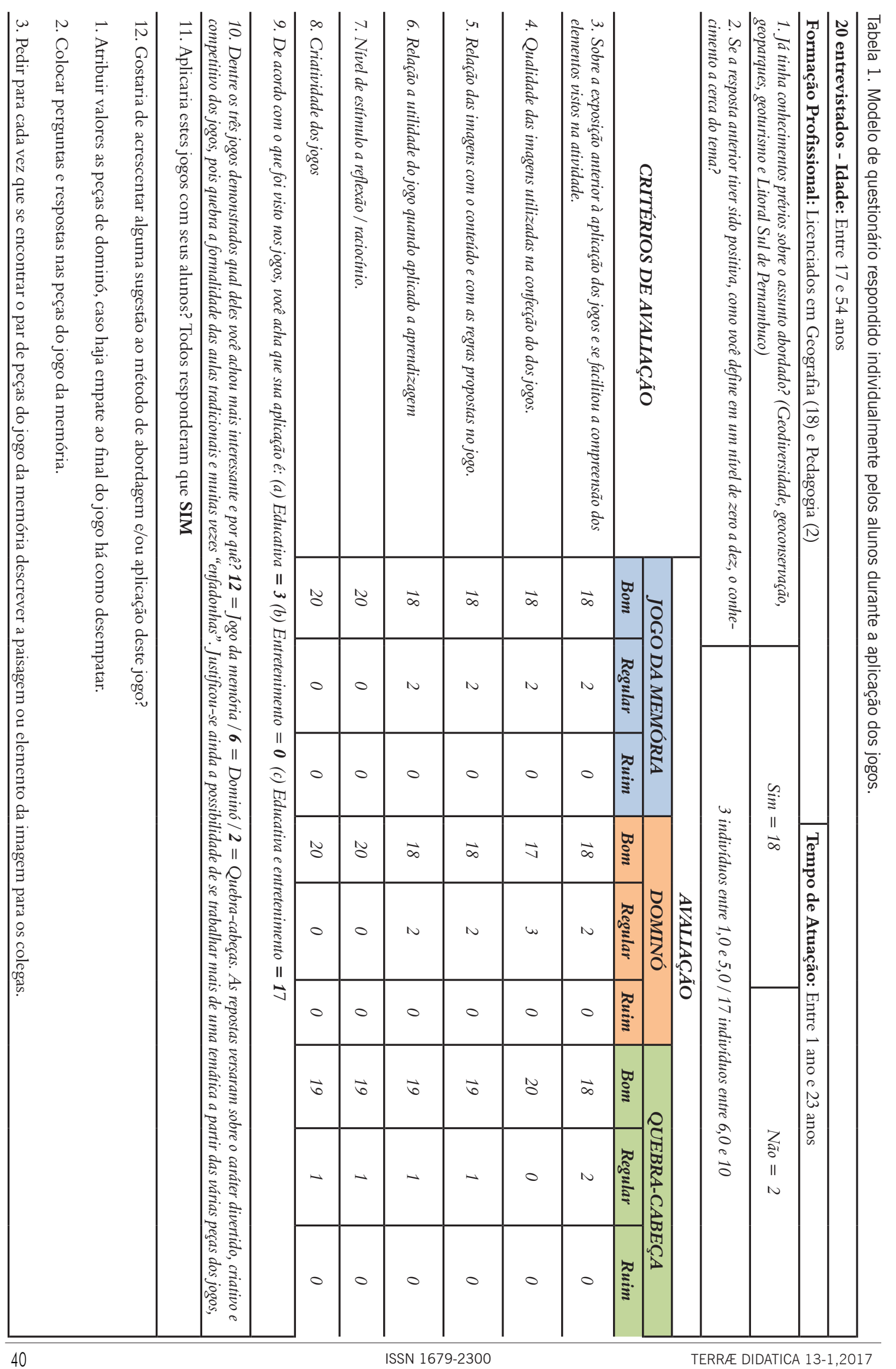


popularização das Geociências.

\section{Considerações Finais}

As Geociências se configuram amplas e complexas e, dependendo da área, a sofisticação dos seus métodos e de seus resultados pode aumentar e/ou dificultar a compreensão do indivíduo leigo no assunto. Desse modo, independentemente do processo educativo ser formal ou não formal, vê-se o desenvolvimento de projetos de popularização em museus, feiras, escolas, universidades, geoparques e parques naturais em todas as esferas governamentais, bem como por pesquisadores e entusiastas independentes, de que é bom exemplo a criação e manutenção do Museu do Una, na vila de pescadores da Várzea do Una, no Litoral Sul de Pernambuco.

Sabe-se que no Brasil, principalmente nas escolas de cidades pequenas e em áreas mais periféricas, os recursos financeiros para atividades que "extrapolem os limites da educação formal" são poucos ou quase nenhum. Nesse contexto, a criatividade e disposição dos profissionais se tornam imprescindíveis no que diz respeito à confecção e/ou adaptação de recursos didáticos que estejam direcionados aos temas das Geociências.

Por tal razão, sugere-se a adaptação de entretenimentos simples, como jogos de memória, dominós, quebra-cabeças e outros jogos de tabuleiro, onde podem ser desenvolvidas atividades educativas e lúdicas com minerais, rochas, paisagens, processos geológicos, entre todas as outras possibilidades que a imaginação permitir.

O incentivo ao desenvolvimento de projetos e a abertura de mais espaços destinados à popularização das Geociências são imprescindíveis para que ela se expanda e haja continuidade deste trabalho de educação e conscientização de crianças, jovens e adultos sobre os elementos da Terra e toda carga histórica e cultural que carregam.

Diante do exposto conclui-se que os jogos geoeducativos se configuram como uma ferramenta alternativa e que, por meio da abordagem interdisciplinar e de atividades lúdicas, envolvendo os elementos locais, como geodiversidade, biodiversidade, história e cultura serão capazes de despertar maior interesse e promover o aprendizado acerca dos elementos naturais e sociais.

Trata-se assim de uma proposta integradora, que estimula uma maneira de pensar em conjunto, reconhecendo que os elementos formam um sistema interligado. Desse modo, a informação e a conscientização a partir destas e de outras ações educativas devem ser a base de sustentação da geoconservação e uma ponte que liga as Geociências à sociedade.

\section{Agradecimentos}

Os autores agradecem a Coordenação de Aperfeiçoamento de Pessoal de Nível Superior (CAPES) pelo investimento e apoio financeiro dado ao projeto de doutorado e intercâmbio (PDSE), realizado na Universidade de Trás-os-Montes e Alto Douro (Portugal), concedido a Thaís Guimarães e que possibilitou o desenvolvimento desta pesquisa. A Faculdade Faintvisa (Faculdades Integradas da Vitória de Santo Antão) e aos alunos que contribuíram com este trabalho. Nossos agradecimentos ao revisor anônimo pelas sugestões e contribuições prementes que enriqueceram este trabalho.

\section{Referências}

Barreto A.M.F., Brilha J.B.R., Almeida J.A.C., Sales A.M.F., Ghilardi A. 2013. Tesouros do Araripe. Recife: Ed. Univ. UFPE. 23p.

Branner J.C. 1904. The stone reefs of Brazil their geological and geographical relations with a chapter on the coral reefs. In: Bul. of the Museum Comp. Zoology at Harvard College, Cambridge, 44(7):285.

Carcavilla Urqui L. 2012. Geoconservación. Ed. Los libros de la Catarata, $128 \mathrm{p}$.

Carneiro C.D.R., Toledo M.C.M., Almeida F.F.M. 2004. Dez motivos para a inclusão de temas de Geologia na Educação Básica. Rev. Bras. Geoc., 34(4):553-560.

Coimbra J.A.A. 2000. Considerações sobre a Interdisciplinaridade. In: Philippi Jr. A., Tucci C.E.M., Hogan D. J., Navegantes R. eds. 2000. Interdisciplinaridade em Ciências Ambientais. São Paulo: Ed. Signus. p. 52-70.

Coombs P.H., Ahmed M. 1974. Attacking rural poverty: How non-formal education can help. Baltimore: John Hopkins Univ. Press. 292p.

CPRH. Agência Estadual do Meio Ambiente. 2001. Diagnóstico Socioambiental. Litoral Sul de Pernambuco. Recife: CPRH. 89p.

Darwin, C. 1841. On a remarkable bar of sandstone off Pernambuco, on the coast of Brazil. London, Edinburgh and Dublin Phil. Mag. and J. Science. 19(3):257-260.

Dib C.Z. 1988. Formal, non-formal and informal education: concepts/applicability. In: Interamerican Conference on Physics Education, Oaxtepec, Mexico, 1987. Anais... New York, American In- 
stitute of Physics, p.300-315. URL: http://www. techne-dib.com.br/downloads/6.pdf. Acesso 03.01.2016.

Dierking L.D. 2005. Lições sem limite: como o aprendizado por livre escolha vem transformando a educação em ciência e tecnologia. História, Ciências, Saúde - Manguinhos, 12(supl.):145-60.

Donslund A., Lemkow N. 2015. Geokids. In: European Geoparks Conference. Anais...Oulu, EGN Conference, p51. URL: http://www.europeangeoparks.org/wp-content/uploads/2012/02/ Book-of-Abstracts-EGN-conference-2015.pdf. Acesso 25.06.2016.

Gaspar A. 1992. O ensino informal de ciências: de sua viabilidade e interação com o ensino formal à concepção de um centro de ciências. Florianópolis: Cad. Cat. de Ens. Física, 9(2):157-163.

Gaspar A. 2002. A educação formal e a educação informal em ciências. In: Massarani L., Moreira I.C., Brito F. eds. 2002. Ciência e público: caminhos da divulgação científica no Brasil. Rio de Janeiro, Fórum de Ciência e Cultura. 232p.

Gonçalves C.W.P. 2008. Os (des) caminhos do meio ambiente. $14^{\mathrm{a}}$ ed. São Paulo: Ed. Contexto. 148p.

Guimarães T. O., Mariano G. 2014. Uso de trilhas como recurso didático: abordagem interdisciplinar no ensino das Geociências. Estudos Geológicos. 24(1):89-103.

Jacobucci D.F.C. 2008. Contribuições dos espaços não-formais de educação para a formação da cultura científica. Em Extensão, Uberlândia, 7(1):55-66.

Lima Filho M., Barbosa J.A., Souza E.M. 2006. Eventos tectônicos e sedimentares nas Bacias de Pernambuco e da Paraíba: implicações no quebramento do Gondwana e correlação com a bacia do Rio Muni. São Paulo, UNESP, Geociências, 25(1):117-126.

Marandino M., Silveira R.V.M., Chelini M.J., Fernandes A.B., Rachid V.A., Martins L.C., Lourenço M.F., Fernandes J.A., Florentino H.A. 2004. A educação não-formal e a divulgação científica: o que pensa quem faz? In: IV Encontro Nacional de Pesquisa em Ensino de Ciências, Bauru, 26-29.12.2003. Anais... Bauru, ENPEC, p1-13. URL: http://www.geenf.fe.usp.br/v2/wp-content/ uploads/2013/09/Educa\%C3\%A7\%C3\%A3on\%C3\%A3o-formal.pdf. Acesso 10.10.2015

Mariano G., Barbosa A. 2008. Riolito, o Vulcão Pernambucano. Terree Didatica, 3(1):92-96.

Morin E. 2012. A cabeça bem-feita: repensar a reforma, reformar o pensamento. $20^{\mathrm{a}}$ ed. Trad. Eloá Jacobina. Rio de Janeiro: Bertrand Brasil. 128p.

Morin E. 2011. Introdução ao pensamento complexo. Trad. Eliane Lisboa, $4^{\mathrm{a}}$ ed. Porto Alegre: Sulina. 124p.

Navas A.M. 2008. Concepções de popularização da ciência e da tecnologia no discurso político: impactos nos museus de Ciências. São Paulo: Fac. Educ. Univ. São Paulo. 240p. (Dissert. . Mestr.).

Nelson L.J., Cushion C.J., Potrac P. 2006. Formal, Non-formal and Informal Coach Learning: A Holistic Conceptualisation. Int. J. Sports Science E Coaching, 1(3):247-259.

Pinto L.M.C.S. 2007. Educação não-formal um contributo para a compreensão do conceito e das práticas em Portugal. Lisboa: Inst. Sup. Ciências do Trabalho e da Empresa, ISCTE. 126p. (Dissert. Mestr.).

Rozakis V., Valiakos I., Mpentanal K., Burlando M., Duarte A., Woodley-Stewart C., Zouros N. 2015. Geoeducation in Action. In: European Geoparks Conference. Anais...Oulu, EGN Conference, p50. URL: http://www.europeangeoparks.org/ wp-content/uploads/2012/02/Book-of-AbstractsEGN-conference-2015.pdf. Acesso 25.06.2016.

UNESCO. Organização das Nações Unidas para a educação, a ciência e a cultura. 2014. Global Geoparks. URL: http://www.unesco.org/new/ en/natural-sciences/environment/earth-sciences/ global-geoparks/. Acesso 02.11.2015.

Vargas V.M.F. 2000. Projetos em Ciências Ambientais: Relato de Casos. In: Philippi Jr. A., Tucci C.E.M., Hogan D. J., Navegantes R. eds. 2000. Interdisciplinaridade em Ciências Ambientais. São Paulo: Ed. Signus. p. 156-168.

Resumo: A preocupação em popularizar as Geociências está presente em todos os aspectos das temáticas que abrangem a geodiversidade, a geoconservação, o patrimônio geológico, o geoturismo e os geoparques. Popularizar os elementos abióticos é contribuir para que a sociedade desperte e reconheça a importância de praticar a geoconservação. Este trabalho destaca a relevância do processo educativo a partir de atividades voltadas para a educação formal e não formal. Assim, sugere alternativas que possam facilitar a compreensão de alunos e do público em geral, norteadas por atividades pautadas na interdisciplinaridade, geoconservação e popularização das Geociências. Para isso, foram elaborados protótipos de "jogos geoeducativos", tendo como proposta aplicá-los em espaços educacionais formais e não. Nesse sentido, foram realizadas pesquisas bibliográficas e vivenciadas experiências in loco, como visitas a museus, geoparques e participação em workshops. A partir do conhecimento adquirido com este trabalho ratifica-se a importância da utilização de materiais específicos direcionados à geodiversidade e ao patrimônio geológico.

PALAVRAS-CHAVE: Educação não formal, geoconservação, popularização das Geociências, Litoral Sul de Pernambuco. 